\title{
ORDERING EXTREMES OF SCALE RANDOM VARIABLES UNDER ARCHIMEDEAN COPULA
}

\section{Ghobad Barmalzan*, Seyed Masih Ayat and Abbas Akrami}

Abstract. In this paper, we discuss the hazard rate order and reversed hazard rate order of parallel and series systems when the components follow general scale model under Archimedean copula for dependence. Several examples are presented for illustrations as well.

Mathematics subject classification (2010): 60E15, 90B25.

Keywords and phrases: Archimedean copula, hazard rate order, reversed hazard rate order, scale model, extreme order statistics.

\section{REFERENCES}

[1] E. Amini-Seresht, J. Qiao, Y. Zhang, P. ZhaO, On the skewness of order statistics in multipleoutlier PHR models, Metrika, 79, (2016), 817-836.

[2] R. B. BAPAT, S. C. KOCHAR, On likelihood-ratio ordering of order statistics, Linear Algebra and Its Applications, 199, (1994), 281-291.

[3] P. J. Boland, E. El-Neweini, F. Proschan, Applications of the hazard rate ordering in reliability and order statistics, Journal of Applied Probability, 31, (1994), 180-192.

[4] J. L. Bon, E. PAltaneA, Comparisons of order statistics in a random sequence to the same statistics with i.i.d. variables, ESAIM: Probability and Statistics, 10, (2006), 1-10.

[5] H. A. David, H. N. Nagaraja, Order Statistics, 3rd ed., Hoboken, New Jersey: John Wiley \& Sons, (2003).

[6] W. DinG, J. YANG, X. LING, On the skewness of extreme order statistics from heterogenous samples, Communication in Statistics-Theory and Methods, 46, (2017), 2315-2331.

[7] L. FAng, X. Zhang, Stochastic comparison of series systems with heterogeneous Weibull components, Statistics \& Probability Letters, 83, (2013), 1649-1653.

[8] R. FANG, C. LI, X. LI, Stochastic comparisons on sample extremes of dependent and heterogeneous observations, Statistics, 50, (2016), 930-955.

[9] R. FAnG, X. LI, Ordering extremes of interdependent random variables, Communications in Statistics-Theory and Methods, 47, (2019), 4187-4201.

[10] T. Hu, Monotone coupling and stochastic ordering of order statistics, System Science and Mathematical Sciences, 8, (1995), 209-214.

[11] B. E. Khaledi, S. FARsinezhad, S. C. Kochar, Stochastic comparisons of order statistics in the scale model, Journal of Statistical Planning and Inference, 141, (2011), 276-286.

[12] S. C. Kochar, M. XU, On the skewness of order statistics with applications, Annals of Operations Research, 212, (2014), 127-138.

[13] C. LI, R. FAng, X. LI, Stochastic comparisons of order statistics from scaled and interdependent random variables, Metrika, 79, (2015), 553-578.

[14] X. LI, R. FANG, Ordering properties of order statistics from random variables of Archimedean copulas with applications, Journal of Multivariate Analysis, 133, (2015), 304-320.

[15] C. LI, X. LI, Likelihood ratio order of sample minimum from heterogeneous Weibull random variables, Statistics \& Probability Letters, 97, (2015), 46-53.

[16] A. W. Marshall, I. Olkin, Life Distributions, Springer-Verlag, New York, 2007.

[17] A. J. MCNeIl, J. NeŠLehovÁ, Multivariate Archimedean copulas, D-monotone functions and $l_{1}$ norm symmetric distributions, The Annals of Statistics, 37, (2009), 3059-3097. 
[18] A. MüLler, D. Stoyan, Comparison Methods for Stochastic Models and Risks, John Wiley \& Sons, New York, 2002.

[19] R. B. NeLSEN, An Introduction to Copulas, New York: Springer, 2006.

[20] P. Pledger, F. Proschan, Comparisons of order statistics and of spacings from heterogeneous distributions, In: Optimizing Methods in Statistics (Ed., J. S. Rustagi), pp. 89-113, Academic Press, New York, (1971).

[21] M. Z. RAQAB, W. A. AMIN, Some ordering results on order statistics and record values, IAPQR Transactions, 21, (1996), 1-8.

[22] M. Rezapour, M. H. Alamatsaz, Stochastic comparison of lifetimes of two $(n-k+1)$-out-of$n$ systems with heterogeneous dependent components, Journal of Multivariate Analysis 130, (2014), $240-251$.

[23] M. Shaked, J. G. Shanthikumar, Stochastic Orders, Springer-Verlag, New York, 2007.

[24] Y. Zhang, X. Cai, P. Zhao, H. Hairu WAng, Stochastic comparisons of parallel and series systems with heterogeneous resilience-scaled components, Statistics, 53, (2018), 126-147.

[25] P. Zhao, N. Balakrishnan, Some characterization results for parallel systems with two heterogeneous exponential components, Statistics, 65, (2011a), 593-604.

[26] P. ZHAO, N. BALAKRISHNAN, MRL ordering of parallel systems with two heterogeneous components, Journal of Statistical Planning and Inference, 141, (2011b), 631-638. 